\title{
Pendampingan Penerapan Aplikasi Pembelajaran Bahasa Inggris Berbasis IT bagi Guru Bahasa Inggris
}

\author{
Nirwanto Maruf ${ }^{*}$, Dahlia Husain ${ }^{2}$, Nuri Rahmiati ${ }^{3}$ \\ ${ }^{1}$ Magister Pendidikan Bahasa Inggris, Universitas Muhammadiyah Gresik, Jl. Sumatra No.101, Kabupaten Gresik, Jawa \\ Timur, Indonesia, 61121. \\ ${ }^{2}$ Program Studi Sastra Inggris, Universitas Muhammadiyah Gorontalo, Jl. Prof. Mansoer Pateda, Pentadio Timur, \\ Kabupaten Gorontalo, Gorontalo, Indonesia, 881136. \\ ${ }^{3}$ MTs. Negeri 2 Lamongan, Jl. Raya Glagah No. 12, Kabupaten Lamongan, Jawa Timur, Indonesia, 62292. \\ *Email koresponden: nirwanto.maruf@umg.ac.id
}

\section{ARTICLE INFO}

Article history

Received: 16 Nov 2021

Accepted: 14 Des 2021

Published: 31 Des 2021

\section{Kata kunci:}

CHATBOT;

E-learning;

Mobile devices;

Pembelajaran berbasis

IT;

SMART RECTORMU;

\begin{abstract}
A B S T R A K
Background: Pembelajaran jarak jauh telah menjadi sumber pembelajaran utama sejak pandemi covid-19 melanda dunia. Sayangnya, lebih banyak penelitian menunjukkan bahwa pembelajaran jarak jauh menghadapi banyak kendala, sehingga tujuan pembelajaran tidak tercapai. Pengabdian masyarakat ini bertujuan untuk membantu para guru Bahasa Inggris dalam mengimplementasikan aplikasi pembelajaran Bahasa Inggris Berbasis IT yaitu Chatbot dan Smart Rektormu. Guru-guru yang dipilih sebagai mitra adalah guru MTs Negeri Lamongan 2. Metode: Pelaksanaan pengabdian ini mengikuti langkah-langkah, yaitu; melakukan penelitian pendahuluan, melakukan analisis kebutuhan, mengadakan seminar, mengadakan lokakarya, dan kemudian melakukan pemantauan dan evaluasi. Hasil: Guru memahami dan menguasai konsep dan pengaplikasian metode pembelajaran e-learning dengan menggunakan mobile devices seperti smart phone, tablet, dan laptop. Kesimpulan: Pengetahuan guru-guru Bahasa Inggris di MTS Negeri 2 Lamongan telah mengalami peningkatan secara signifikan terkait pengetahuan pengaplikasian dan metode e-learning dengan menggunakan mobile devices.
\end{abstract}

\section{A B S T R A C T}

\section{Background: Distance learning has been a major source of learning since the covid-19 pandemic hit the world. Unfortunately, more research shows that distance learning faces many obstacles, so learning goals are not achieved. This community service aims to assist English teachers in implementing IT-based English learning applications, namely Chatbot and Smart Rector. The teachers chosen as partners are teachers of Lamongan State MTs 2. Method: The implementation of this devotion follows the steps, that is; conduct preliminary research, conduct needs analysis, hold seminars, hold workshops, and then conduct monitoring and evaluation. Results: Teachers understand and master the concept and application of e-learning methods by using mobile devices such as smart phones, tablets, and laptops. Conclusion: The knowledge of English teachers at MTS Negeri 2 Lamongan has significantly improved in terms of application knowledge and e-learning methods using mobile devices. \\ Keyword: \\ E-learning; \\ IT-based learning; \\ SMART RECTORMU;}

\section{PENDAHULUAN}

Pandemi Covid-19 yang melanda dunia saat ini, telah merubah tatanan sosial budaya masyarakat dunia tidak terkecuali di bidang Pendidikan. Tatanan pembelajaran berubah dari pembelajaran tatap muka menjadi sesuatu yang baru bagi pendidik, siswa dan orang tua siswa yaitu 
pembelajaran jarak jauh (PJJ) dengan berbagai macam platform pembelajaran daring. Tatanan baru ini merupakan tantangan dan sekaligus masalah yang muncul dalam proses pembelajaran. Penerapan PJJ dengan menggunakan berbagai platform pembelajaran daring belum menghasilkan pembelajaran yang optimal bagi siswa sehingga learning outcome yang diinginkan tidak tercapai. Hal ini ini sebabkan karena: 1) siswa tidak memiliki budaya PJJ, 2) para pendidik masih berfokus pada lesson study, belum memprioritaskan pada aplikasi IT dalam pembelajaran, 3) tidak mahirnya para pendidik dalam menggunakan aplikasi pembelajaran online yang tersedia, sehingga metode pembelajaran yang digunakan sifatnya monoton dan membosankan bagi peserta didik, 4) metode pengajaran yang diberikan tidak dalam bentuk cooperative learning sehingga siswa tidak saling dapat berinteraksi dengan siswa lainnya dalam proses pembelajaran (Purwantoro et al., 2021; Maruf \& Anjely, 2020).

Berangkat dari permasalahan tersebut, maka kami sebagai tim PKM menawarkan solusi kepada para pendidik sehingga learning outcome yang ditargetkan oleh para pendidik dapat tercapai. Adapun aplikasi pembelajaran tersebut adalah Chatbot dan Smart Rectormu. Chatbot adalah applikasi yang dapat digunakan sebagai solusi bagi permasalahan dalam pembelajaran khususnya pembelajaran English speaking skill (Ranoliya et al., 2017).

Hasil yang dapat diperoleh dari kegiatan ini: 1) para guru dapat menguasai aplikasi pembelajaran Bahasa Inggris berbasis IT untuk meningkatkan kemampuan siswa dalam hal speaking, reading, dan writing, 2) meningkatkan strategi/metode pembelajaran guru sehingga penyampaian materi tidak monoton dan membosankan, 3) penerapan cooperative learning pada mobile learning dalam pembelajaran sehingga siswa dapat saling berinteaksi dalam proses pembelajaran, 4) meningkatkan kemampuan guru dalam mendesain, mengimplementasikan dan mengevaluasi pembelajarn berbasis e-learning.

\section{MASALAH}

Berdasarkan research di lapangan dan hasil wawancara dengan para guru di sekolah mitra yang diperoleh oleh Tim PKM, telah berhasil mengidentifikasi permasalahan yang dimiliki oleh guru-guru di sekolah Mitra yaitu MTs. Negeri 2 Lamongan adalah sebagai berikut:

1. Minimnya pengetahuan dan kemampuan guru dalam penggunaan aplikasi pembelajaran berbasis IT di sekolah.

2. Proses pembelajaran tidak mengakomodir metode cooperative learning sehingga tidak ada proses interaksi antar siswa dalam proses pembelajaran.

3. Proses assessment atau evaluasi pembelajaran yang masih manual, tidak berbasis IT yang sifatnya automatic assessments yang dapat memberikan gambaran umum secara instant tentang kemampuan siswa dalam hal speaking, reading dan writing.

4. Minimnya kegiatan program pelatihan atau workshop untuk para guru tentang proses pembelajaran berbasis IT dalam hal ini penggunaan aplikasi pembelajaran sebagai upaya peningkatan pencapaian pembelajaran peserta didik.

Merujuk pada permasalahan yang dihadapi oleh para guru di sekolah mitra tersebut di atas, dan juga pada analisis kebutuhan terhadap penggunaan aplikasi pembelajaran berbasis IT, maka tim PKM memprioritaskan pada peningkatan kemampuan guru dalam penerapan aplikasi 
pembelajaran berbasis IT khususnya pembelajaran Bahasa Inggris sebagai upaya meningkatkan pencapaian belajar siswa dalam hal ini speaking, reading, dan writing sehingga learning outcome dapat tercapai.

\section{METODE PELAKSANAAN}

Alur Pelaksanaan

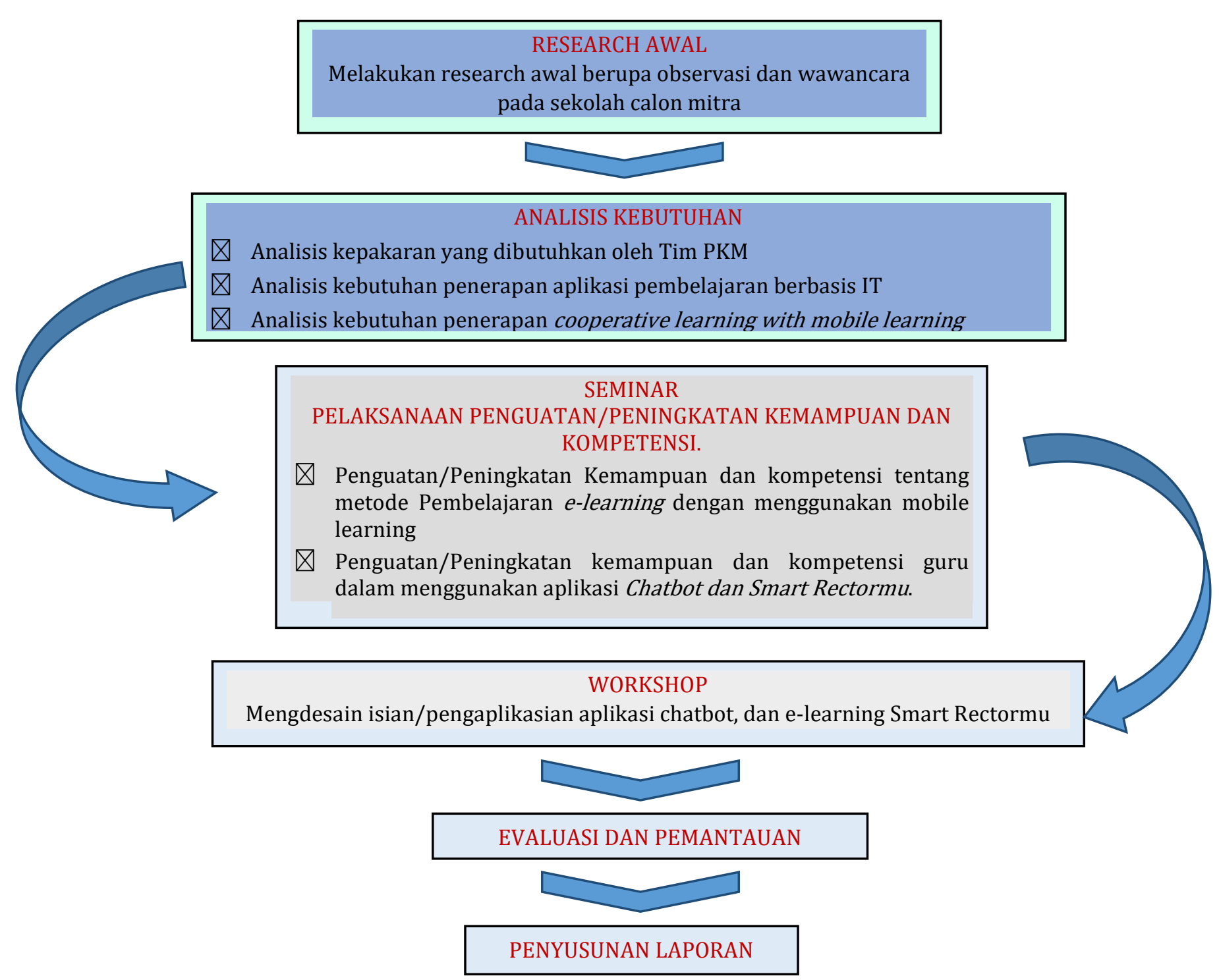

Gambar 1. Alur Pelaksanaan Kegiatan (Sumber: Diolah oleh tim PKM)

\section{Pelaksanaan Pendampingan dan Workshop}

1. Pelaksanaan pendampingan dan workshop pembelajaran Bahasa Inggris dengan menggunakan aplikasi e-learning CHATBOT selama 2 (dua) hari yaitu pada tanggal 04 Oktober dan 06 Oktober 2021 secara luring atau offline, dengan jumlah peserta sebanyak 9 (sembilan) orang guru di sekolah mitra tersebut. Hari pertama dalam bentuk pengenalan berupa penjelasan terkait manfaat, dan fungsi/sistem kerja aplikasi CHATBOT yang dilaksanakan dalam bentuk seminar pada tanggal 04 Oktober 2021 secara luring atau offline. Sedangkan untuk 
pengaplikasian aplikasi $C H A T B O T$ dilaksanakan dalam bentuk workshop pada tanggal 06 Oktober 2021 juga secara luring atau offline.

2. Pelaksanaan pendampingan dan workshop pembelajaran Bahasa Inggris dengan menggunakan aplikasi SMART RECTORMU juga dilaksanakan selama 2 (dua) hari yaitu pada tanggal 05 Oktober 2021 dan 07 Oktober 2021 dilakukan secara luring atau offline, dengan peserta yang sama. Hari ke-3 yaitu pada tanggal 05 Oktober 2021 dalam bentuk pengenalan berupa penjelasan terkait manfaat, dan fungsi/sistem kerja aplikasi e-learning SMART RECTORMU yang dilaksanakan dalam bentuk seminar secara luring atau offline. Sedangkan pada tanggal 07 Oktober 2021, mengdesain isian/pengaplikasian aplikasi SMART RECTORMU yang dikemas dalam bentuk workshop dilakukan secara luring atau offline.

\section{HASIL DAN PEMBAHASAN}

\section{Hasil Tahap Penguatan/Peningkatan Kemampuan dan Kompetensi}

Kegiatan penguatan/peningkatan kemampuan dan kompetensi dilaksanakan dalam bentuk seminar yang mana diikuti oleh para guru- guru Bahasa Inggris yang ada di sekolah mitra yaitu sebanyak 9 orang guru. Kegiatan ini dilaksanakan pada hari pertama dan hari ketiga yaitu pada hari Senin tanggal 04 Oktober 2021 untuk aplikasi e-learning CHATBOT, dan hari Rabu tanggal 06 Oktober 2021 untuk aplikasi e-learing SMART RECTORMU. Kedua kegiatan tersebut dimulai pukul 09:30 hingga pukul 16:30 WIB, yang bertempat di sekolah mitra MTs. Negeri 2 Lamongan.

Pada kegiatan ini, team PKM melakukan knowledge transfer berupa:

1. Peningkatan kemampuan dan kompetensi guru tentang konsep dan metode pembelajaran berbasis IT (e-learning with mobile devices).

2. Peningkatan kemampuan dan kompetensi guru tentang konsep dan metode cooperative learning dalam pembelajaran e-learning (Purwantoro et al., 2021).

3. Peningkatan kemampuan dan kompetensi guru dalam memahami konsep, tujuan, dan fungsi kerja aplikasi e-learning CHATBOT dan aplikasi e-learning SMART RECTORMU dalam pembelajaran reading dan writing (Arifani \& Suryanti, 2020).

Hasil atau output yang didapatkan dalam kegiatan tersebut di atas adalah: 1) para guru memahami dan menguasai konsep dan metode pembelajaran e-learning with mobile learning, 2) para guru kemudian mampu memahami dan menguasai konsep dan metode cooperative learning dalam pembelajaran e-learning, 3) para guru memahami dan menguasai konsep, tujuan, kegunaan, dan fungsi kerja aplikasi e-learning CHATBOT dan aplikasi e-learning SMART RECTORMU, 4) para guru mampu memahami dan menguasai tahapan penggunaan aplikasi CHATBOT dan SMART RECTORMU. 


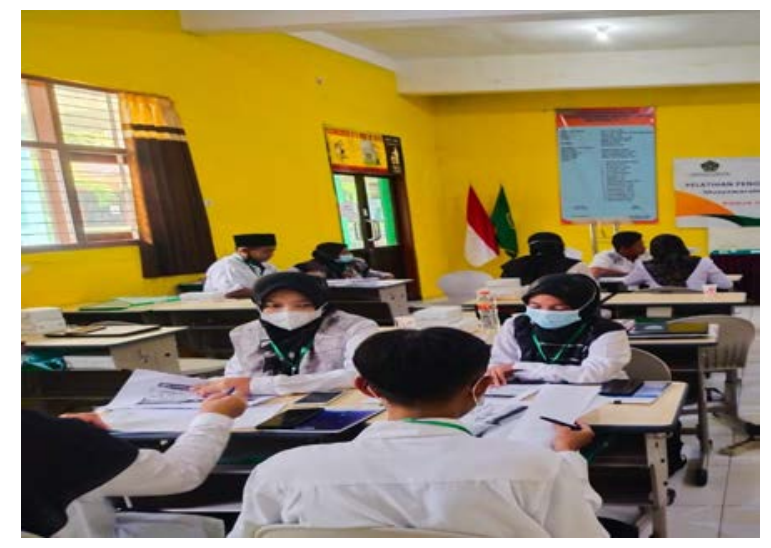

Gambar 2. Peserta Peningkatan/Penguatan Kemampuan dan Kompetensi (04 Oktober 2021 dan 06 Oktober 2021).

\section{Hasil Tahap Workshop}

Kegiatan workshop ini dilaksanakan pada hari ke-2 dan ke-4 yaitu pada hari Selasa tanggal 05 Oktober 2021 untuk kegiatan workshop khusus aplikasi e-learning CHATBOT, sedangkan untuk kegiatan workshop aplikasi e-learning SMART RECTORMU dilaksanakan pada hari Kamis tanggal 07 Oktober 2021, dan keduanya masing-masing dilaksanakan pada pukul 09:30 hingga pukul 16:30 WIB.

Kegiatan workshop ini sangat memberikan manfaat pada mitra dalam hal ini guru-guru yang mana sebelumnya mereka tidak bisa memgaplikasikan aplikasi ataupun software pembelajaran yang berbasis IT. Namun setelah workshop ini dilakukan, mereka kemudian menjadi familiar dengan aplikasi pembelajaran, di samping itu para guru ini dapat mengaplikasikan pembelajaran mereka ke aplikasi CHATBOT dan SMART RECTORMU.

Pada kegiatan workshop ini, team PKM melatih dan sekaligus melakukan praktek langsung pengaplikasian kedua aplikasi e-learning tersebut dengan menggunakan mobile devises baik itu berupa smart phone ataupun Laptop. Pada kegiatan ini mampu meningkatkan: 1) keterampilan para guru dalam mengaplikasikan aplikasi e-learning CHATBOT yang kemudian akan dipraktekan kepada siswa mereka nantinya, 2) para guru mampu dan terampil dalam merancang perangkat pembelajaran pada aplikasi e-learning SMART RECTORMU baik itu berupa video pembelajaran dan pembuatan tugas pembelajaran siswa, 3) mampu mengdesain evaluasi pembelajaran melalui aplikasi e-learning SMART RECTORMU dengan menggunakan mobile devices.

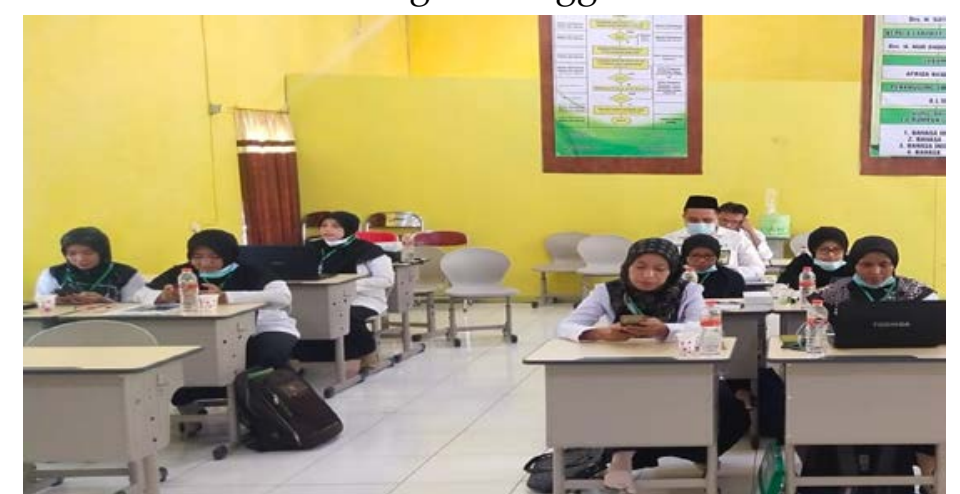

Gambar 3. Kegiatan Workshop Pengaplikasian CHATBOT dan SMART RECTORMU pada Mobile devices (5 Oktober 2021 dan 7 Oktober 2021) 
Penggunaan software atau aplikasi dalam pembelajaran khususnya pembelajaran bahasa merupakan bagian dari sistim pembelajaran yang dikenal dengan nama Computer Assisted Language Learning (CALL) (Shawar, 2017). CALL merupakan system yang digunakan sebagai media proses belajar mengajar bahasa tanpa harus berada di dalam kelas.

CHATBOT merupakan singkatan dari chatting robot. Aplikasi ini merupakan komunikasi simulasi program komputer (Bii, 2013; Dahiya, 2017). Aplikasi CHATBOT ini sebagai media Latihan percakapan Bahasa Inggris, dan merupakan bentuk aplikasi Natural Language Processing (NLP) (Colace et al., 2018; Haristiani, 2019; Sarosa et al., 2020). Aplikasi ini memudahkan komunikasi antara siswa dengan komputer khususnya percakapan Bahasa Inggris (Nghi et al., 2019). Aplikasi ini bertindak sebagai lawan bicara dalam percakapan Bahasa Inggris sehingga seolah - olah siswa sedang melakukan percakapan dengan native speaker (Dahiya, 2017; Kim, 2019) Aplikasi ini menyediakan dua mode percakapan, yaitu mode chat (texting) dan mode voice (suara) (Ranoliya et al., 2017). Teknologi yang digunakan pada mode voice adalah Speech Recognition yang memungkinkan ucapan langsung dialihkan ke dalam teks tertulis, dan Text-to-Speech berfungsi mengkonversi teks tertulis menjadi ucapan (Jia, 2003). Sedangkan Smart Rectormu adalah aplikasi yang digunakan untuk meningkatkan kemampuan pemahaman siswa dalam reading dan kemampuan siswa dalam writing (Arifani \& Suryanti, 2020). Aplikasi ini terdiri dari 10 materi reading dan writing yang dilengkapi dengan automatic assessments yang dapat memberikan gambaran umum tentang kemampuan siswa dalam hal reading dan writing. Di samping itu aplikasi ini juga dapat melakukan penilaian dan mendeteksi kesalahan reading dan writing secara otomatis (Arifani \& Suryanti, 2020). Kedua aplikasi ini dapat difungsikan melalui mobile devices seperti smartphone, tablet, laptop.

Seminar dan workshop ini memberikan pengalaman yang sangat berharga bagi guru-guru sehingga paling tidak mereka menjadi lebih paham dan mampu menerapkan pembelajaran berbasis IT yang kemudian dapat menerapkannya kepada siswa mereka. Pada workshop ini juga, para guru telah melakukan simulasi, dan mengadaptasi isi materi yang sebelumnya telah persiapkan di kedua aplikasi tersebut, sehingga dapat segera diterapkan kepada siswa secara mandiri. Workshop juga terbukti bisa merubah paradigma para guru peserta workshop menuju pembelajaran e-learning yang mudah, fleksibel, dan juga dapat dilakukan kapan saja dan di mana saja sehingga lebih efektif jika dibandingkan dengan pembelajaran model tradisional (Sarosa et al., 2020).

\section{KESIMPULAN}

Dari hasil kegiatan pengabdian kepada masyarakat ini yaitu berupa pelatihan dan pendampingan penguasaan aplikasi pembelajaran Bahasa Inggris berbasis IT bagi guru-guru mitra sekolah yang dikemas dalam bentuk seminar dan workshop, menyimpulkan bahwa pertama, para guru mitra meningkat pengetahuan dan kemampuannya dalam hal pembelajaran berbasis IT, yang tadinya mereka menerapkan model pembelajaran tradisional, namun setelah mengikuti kegiatan ini dapat membuka/meningkatkan wawasan dan pengetahuan mereka untuk bisa menerapkan pembelajaran berbasis IT. Kedua, sebelumnya para guru peserta pelatihan hanya mengenal e-learning madrasah, setelah kegiatan ini mereka menjadi lebih paham dalam penggunaan aplikasi/software pembelajaran e-learning yang dapat diaplikasikan pada mobile devices 
seperti smart phone, tables, dan laptop yang mana dapat dilakukan secara fleksibel (tempat dan waktu), dan hasilnya lebih efektif jika dibandingkan dengan pembelajaran model tradisional .

\section{UCAPAN TERIMA KASIH}

Ucapan terima kasih kepada Kepala Sekolah dan para guru MTs. Negeri 2 Lamongan yang telah memberikan kesempatan kepada tim PKM untuk bersedia menjadi mitra pada kegiatan PKM ini. Terkhusus ucapan terima kasih kepada Direktur Pascasarjana Universitas Muhammadiyah Gresik, Dr. Mu'minatus Sholichah, Dra., Ec., M.Si. yang telah memberikan dukungannya sehingga kegiatan ini dapat terlaksana. Terkhusus lagi diucapkan kepada Dr. Yudhi Arifani, M.Pd. yang telah ikut serta membantu tim PKM sebagai pemateri/narasumber dalam seminar dan workshop terkait Smart Rectormu.

\section{DAFTAR PUSTAKA}

Arifani, Y., \& Suryanti, S. (2020). Empowering Rural Teachers Teaching Reading and Writing Literacies Using a Blended Smart-Rectormu Model 477(Iccd), 791-794. https://doi.org/10.2991/assehr.k.201017.174

Bii, P. (2013). Chatbot technology: A possible means of unlocking student potential to learn how to learn. Educational Research, 4(2), 218-221.

Colace, F., De Santo, M., Lombardi, M., Pascale, F., Pietrosanto, A., \& Lemma, S. (2018). Chatbot for e-learning: A case of study. International Journal of Mechanical Engineering and Robotics Research, 7(5), 528-533. https://doi.org/10.18178/ijmerr.7.5.528-533

Dahiya, M. (2017). A Tool of Conversation: Chatbot, International Journal of Computer Sciences and Engineering, Volume-5, Issue-5 E-ISSN: 2347-2693. International Journal of Computer Sciences and Engineering (JCSE), 5(December).

Haristiani, N. (2019). Artificial Intelligence (AI) Chatbot as Language Learning Medium: An inquiry. Journal of Physics: Conference Series, 1387(1). https://doi.org/10.1088/17426596/1387/1/012020

Jia, J. (2003). The Study of the Application of a Keywords-based Chatbot System on the Teaching of Foreign Languages. 1-11. http://arxiv.org/abs/cs/0310018

Kim, N. (2019). A Study on the Use of Artificial Intelligence Chatbots for Improving English Grammar Skills. Journal of Digital Convergence, 17(8), 37-46. https://doi.org/10.14400/JDC.2019.17.8.037

Nghi, T. T., Phuc, T. H., \& Thang, N. T. (2019). Applying ai chatbot for teaching a foreign language: An empirical research. International Journal of Scientific and Technology Research, 8(12), 897-902.

Maruf, N., \& Anjely, A. M. R. (2020). Utilizing Cooperative Integrated Reading and Composition (CIRC) with mobile Learning to Enhance Students' Reading Comprehension. Jurnal Bahasa Dan Sastra Inggris, 9(2), 10-19. https://doi.org/10.31314/british.9.2.\%25p.2020 
Purwantoro, A., Asari, S., \& Maruf, N. (2021). The Effectiveness of E-Learning Madrasah in English Teaching and Learning. BIRCI-Journal, 4(3), 5234-5244. https://doi.org/10.33258/birci.v4i3.2314

Ranoliya, B. R., Raghuwanshi, N., \& Singh, S. (2017). Chatbot for university related FAQs. 2017 International Conference on Advances in Computing, Communications and Informatics, ICACCI 2017, 2017-Janua(January), 1525-1530. https://doi.org/10.1109/ICACCI.2017.8126057

Sarosa, M., Kusumawardani, M., Suyono, A., \& Wijaya, M. H. (2020). Developing a social media-based Chatbot for English learning. IOP Conference Series: Materials Science and Engineering, 732(1). https://doi.org/10.1088/1757-899X/732/1/012074

Sarosa, Moechammad, Suyono, A., Kusumawardani, M., \& Sari, Z. (2020). Implementasi Chatbot Pembelajaran Bahasa Inggris menggunakan Media Sosial. JEPIN (Jurnal Edukasi Dan Penelitian Informatika), 6(3), 317-322.

Shawar, B. A. (2017). Integrating CALL Systems with Chatbots as Conversational Partners. Computacion y Sistemas, 21(4), 615-626. https://doi.org/10.13053/CyS-21-4-2868 